\title{
L'immortalité, sujet d'avenir...
}

\section{Jean Martin}

Dr, membre de la rédaction

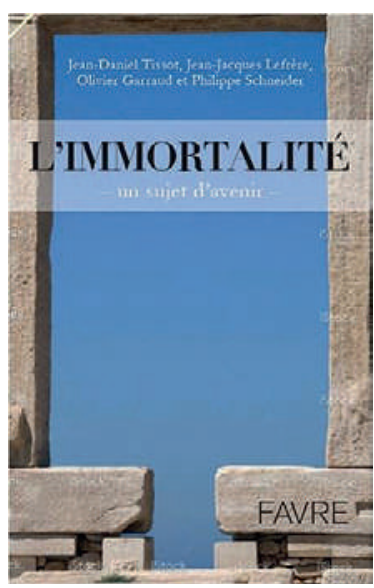

Jean-Daniel Tissot, Olivier Garraud,

Jean-Jacques Lefrère, Philippe Schneider (dir. publ.)

L'immortalité - un sujet d'avenir

Lausanne: Editions Favre; 2014.

436 pages. $44 \mathrm{CHF}$.

ISBN 978-2-8289-1444-8

Cet ouvrage est d'abord un objet élégant: couverture et illustrations attrayantes, belle typographie, on a plaisir à le parcourir. Rassemblement de 25 contributions par une trentaine d'auteurs: douze médecins (dont un historien, un psychiatre, un éthicien, un légiste), trois biologistes, sept auteurs du domaine des lettres (enseignants et chercheurs pour la plupart), quatre théologiens, cinq autres enfin.

Avec une préfacière prestigieuse, Elizabeth Blackburn, Prix Nobel 2009. Extrait: «En règle générale, dit-elle, en tant que scientifique, je suis peu encline à faire des déclarations au sujet de l'immortalité. Pourquoi suis-je prise dans ces discussions? C'est que ma recherche a été centrée sur les télomères et la télomérase, [que certains surnomment] «l'enzyme de l'immortalités, qui pourrait permettre à des cellules - du moins chez les unicellulaires - de proliférer apparemment indéfiniment. [...] Mais il n'est pas rare que les discussions soient rapidement polluées par l'idée d'étendre indéfiniment la durée de la vie humaine, donnant lieu à des spéculations et comportant le risque d'orgueil (hubris).»

\section{Vaste palette}

Le livre réunit une vaste palette de présentations et réflexions de haut niveau, dans plusieurs registres. Qu'on en juge: je me suis essayé à une répartition quantitative, donc brute (en fonction de nombres de pages), selon les champs disciplinaires: grosso modo, quatre domaines comptent chacun pour un cinquième de l'ouvrage: 1) les aspects biologiques (y compris médicaux, minoritaires toutefois, ainsi que de biologie animale); 2) des textes traitant des idées et de leur évolution, philosophie, histoire et littérature (avec quelques morceaux de fiction); 3) des contributions par quatre théologiens, dont trois sont aussi physiciens - avec un contenu en conséquence - l'auteur psychiatre parle de son côté aussi de neuro-théologie; 4) la (socio-)anthropologie. Des contributions substantielles sur "Mathématiques et immortalité», sur les aspects juridiques (propriété intellectuelle dignité humaine) et sur "Monuments immortels» constituant le dernier cinquième.

\section{Une étude "classique» de l'immortalité}

Que je mentionne, en toute humilité, un peu de surprise en parcourant le contenu de "L'immortalité», liée à un biais personnel. Je me suis beaucoup préoccupé au cours des dernières années de bioéthique et ai été amené à lire et entendre passablement de choses, sophistiquées ou populaires, sérieuses ou ébouriffées, sur notre possible marche vers l'immortalité, sur cette terre, par les voies du transhumanisme ou du posthumanisme (on pense à Aubrey de Grey, Ray Kurzweil, quelques autres). Je m'attendais donc à voir des textes sur l'humanité prolongée (pour quelque temps, pour longtemps?), thème de plus en plus fréquemment évoqué dans la littérature scientifique et la presse grand public. Le fantasme de l'immortalité, ici, pour demain: un cauchemar à mon sens, de nouveaux résidants, les enfants, ne seraient plus du tout bienvenus. Des espoirs alimentés par les merveilles de la biologie et des technologies actuelles ou à venir: Elizabeth Blackburn et la télomérase, les cellules-souches, les prothèses de tous genres toujours plus fines et performantes, de mieux en mieux routinisées. 


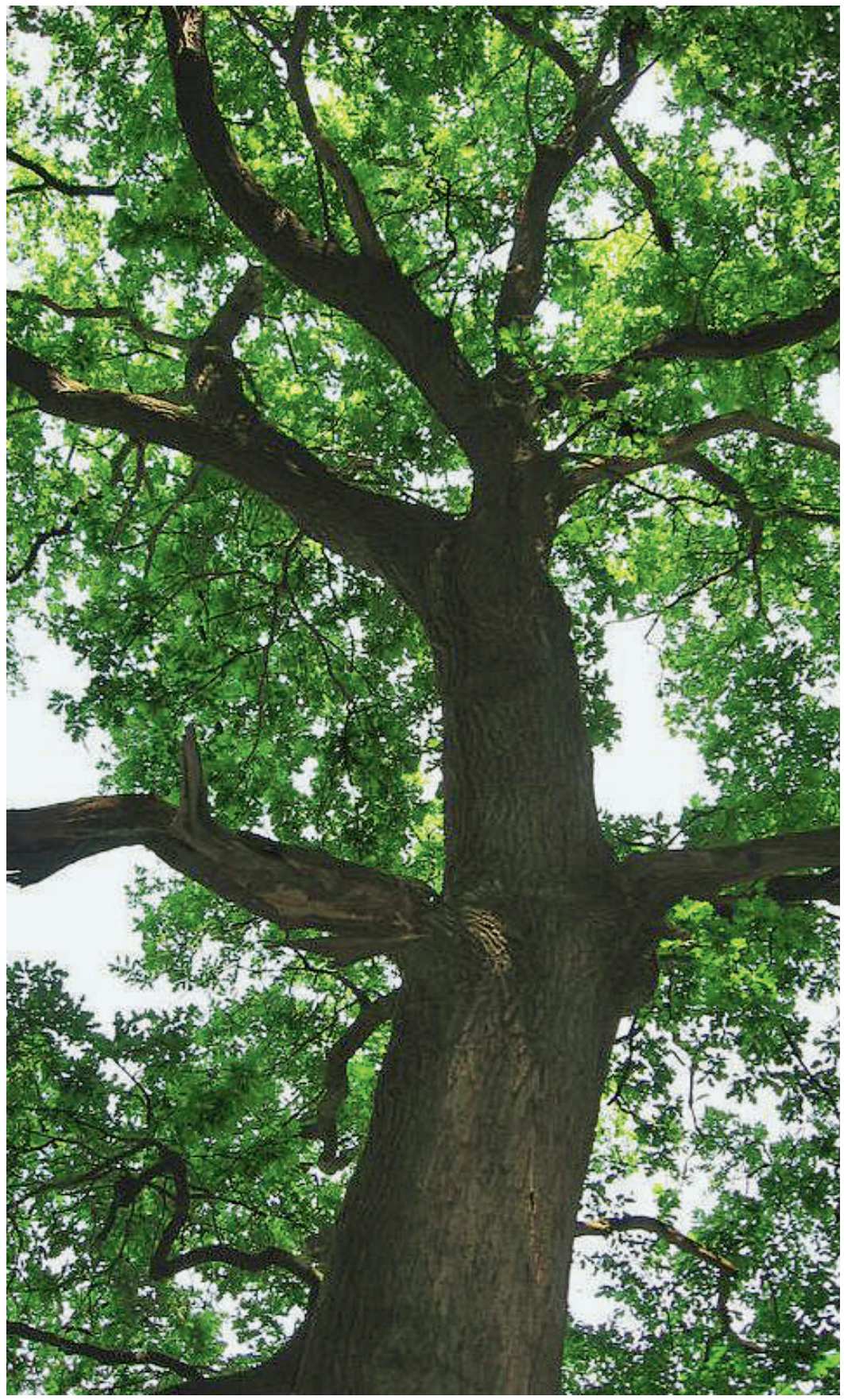

L'arbre, symbole de force vitale aussi bien que de finitude.

Cette remarque est là pour relever que ces aspects ne sont pas un propos principal du livre présenté ici, où l'immortalité est étudiée surtout dans ses aspects «classiques» du registre des sciences humaines, philosophie, théologie (l'immortalité ailleurs que dans ce monde) - avec aussi, je l'ai indiqué, des contributions biologiques. Il est bon et nécessaire que ces dimensions soient traitées de manière approfondie et pas seulement telles «sculptures sur nuage» selon quoi nos congénères qui vivront éternellement sur cette terre sont déjà nés, ou peu s'en faut.

\section{La vie immortelle, une aspiration de l'homme?}

Difficile de rendre justice à une somme aussi diverse et dense, pas possible en quelques paragraphes. Quelques passages que j'ai notés - sans prétention de représentativité. L'historien de la médecine V. Barras: «Le biologiste August Weismann (1834-1914) peut prétendre, dans une conférence sur la ‘durée de la vie` publiée en 1881, que la mort n'est pas une obligation inhérente à la vie: les individus meurent mais la vie elle-même est potentiellement immortelle.» Parlant anthropologie, O. Garraud écrit: «L'homme - cet être biologique extrêmement fragile, le seul à naître inachevé et qui doit attendre de l'éducation parentale et de la confrontation à l'environnement une seconde naissance qui l'amènera, seulement après le tiers de sa vie, à l'âge adulte - tend naturellement à durer et, ce faisant, à transmettre pour durer encore au-delà de sa première fin (charnelle). Ce désir d'éternité l'inscrit, nous semble-t-il, dans une dynamique d'aspiration à l'immortalité.» L’architecte M. Culot cite Hannah Arendt: «Si le monde doit contenir un espace public, il ne doit pas être érigé pour une génération et projeté pour les vivants seulement: il doit transcender la vie de l'homme mortel; sans cette transcendance vers une immortalité terrestre potentielle, il ne peut $\mathrm{y}$ avoir de politique et, au sens strict, de commun et de domaine public.» Le juriste $\mathrm{Ch}$. Joye à propos de son domaine: "Prosaïque, le droit est silencieux sur l'immortalité de l'âme. En revanche, il s'intéresse au sort de la chair et peut saisir les actes de l'homme, parfois abominables, qui le font passer à la postérité. [...] Chacun peut prétendre à cette immortalité profane, d'ampleur et de durée variables. [...] Chaque personne est sa propre œuvre d'immortalité.»

Et les médecins Gérard et Sabine Waeber: "Il nous semble que la recherche d'une éternité biologique (organique) reste une chimère pour l'homme moderne. Le seul exemple d'immortalité cellulaire est représenté, en effet, par des processus pathologiques tels que la croissance tumorale. [...] Peut-être que l'immortalité de l'être ne se situe pas au niveau cellulaire, qui reflète seulement une transmission et un héritage partiels, mais doit être cherchée dans des champs plus vastes, comme celui de l'esprit ou de l'âme ou vers d'autres cieux... à la recherche de l'éternité plutôt que de l'immortalité.» 